Portland State University

PDXScholar

5-19-1994

\title{
"I Don't Speak My Own Language": Ethnicity Among the Malayalees of Singapore
}

David L. Moore

Portland State University

Follow this and additional works at: https://pdxscholar.library.pdx.edu/open_access_etds

Part of the Anthropology Commons

Let us know how access to this document benefits you.

\section{Recommended Citation}

Moore, David L., "'I Don't Speak My Own Language": Ethnicity Among the Malayalees of Singapore" (1994). Dissertations and Theses. Paper 4773.

https://doi.org/10.15760/etd.6657

This Thesis is brought to you for free and open access. It has been accepted for inclusion in Dissertations and Theses by an authorized administrator of PDXScholar. Please contact us if we can make this document more accessible: pdxscholar@pdx.edu. 


\section{THESIS APPROVAL}

The abstract and thesis of David I. Moore for the Master of Arts in Anthropology were presented May 19, 1994, and accepted by the thesis committee and the department.

COMMITTEE APPROVALS:

Sharon A. Carstens, Chair

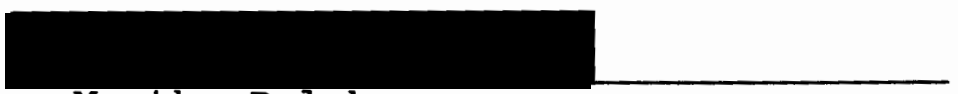

Martha Balshem

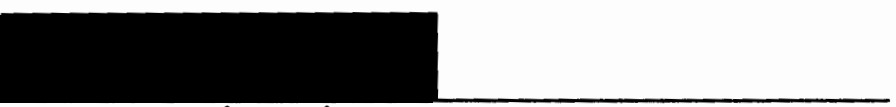

Thomas Biolsi

DEPARTMENT APPROVAL:

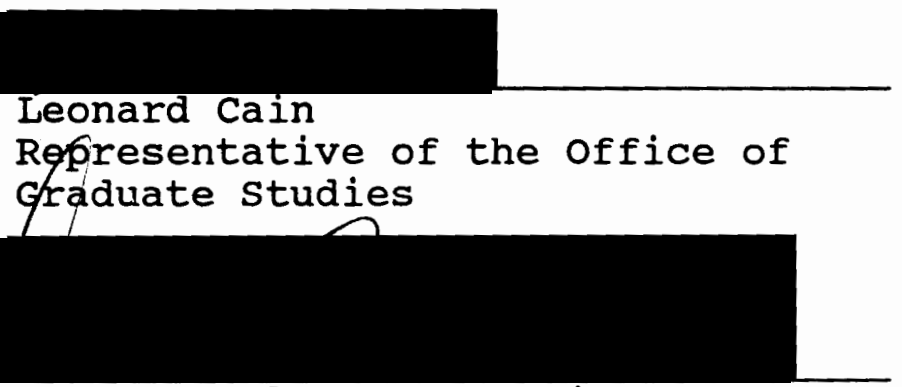

Marc R. Feldesman, Chair

Department of Anthropology

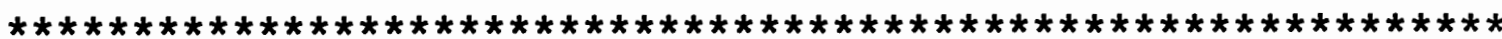

ACCEPTED FOR PORTLAND STATE UNIVERSITY BY THE LIBRARY

by

on

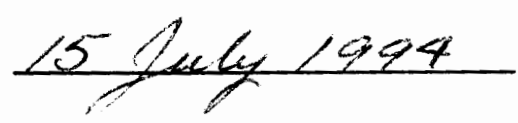




\section{ABSTRACT}

An abstract of the thesis of David $L$. Moore for the Master of Arts in Anthropology presented May 19, 1994.

Title: "I Don't Speak My Own Language": Ethnicity Among the Malayalees of Singapore.

This thesis is an ethnographic examination of the significance of Malayalee ethnicity in Singapore. Ethnic identity is important in the daily lives of singaporeans, due in part to the government-directed public focus in Singapore on the ideal of multiculturalism through which it is asserted that to be singaporean, one must be, in the main, Chinese, Malay, or Indian. But other identities, such as Malayalee, a subset of the larger category "Indian", have not decreased in importance. They, in fact, remain important in identifying what kind of Chinese, Malay, or Indian a person is, as Chinese, Malay, or Indian identifies what kind of singaporean someone is.

In the thesis I focus on a core contradiction in singapore Malayalee culture. In singapore it is perceived as very important to know one's 'mother tongue' in order to know one's culture and heritage. But Malayalees growing up in singapore have not had much chance to learn their 
language, Malayalam, nor have they had much practical use for it outside of the home. Therefore, many singapore Malayalees feel a sense of alienation from Malayalee culture. Many feel they know Iittle about their own culture because they do not speak their own language. With the emphasis on multiculturalism the sense of a distinctive Malayalee culture will remain in singapore, as will the sense of alienation from it felt by many Malayalees.

In the analysis practice theory and the concept of habitus are used to identify how people's actions have been affected by particular historical circumstances, and how their actions have, in turn, structured the form of Malayalee ethnicity in singapore today. It is asserted that practice theory gives a much better explanation of singapore Malayalee ethnicity than primordialist or instrumentalist theories.

There have been only five previous studies of singapore Malayalees, all Bachelor's Honors theses at the National University of Singapore. This study contributes, therefore, to a sparse literature. 
"I DON'T SPEAK MY OWN LANGUAGE":

ETHNICITY AMONG THE MALAYALEES OF SINGAPORE

by

DAVID L. MOORE

A thesis submitted in partial fulfillment of the requirements for the degree of

MASTER OF ARTS

in

ANTHROPOLOGY

Portland State University

1994 


\section{ACKNOWLEDGEMENTS}

This thesis could not have been written without the great deal of help given by many people. First of all I have to thank the many people in singapore who took their time to talk with me, invited me into their homes, and made me feel welcome. This wonderful kindness can never fully be repaid, and I will never forget it.

I must thank my advisor, Dr. Sharon Carstens, for being ever so helpful in getting me to think through my ideas and express them more clearly, and for being invaluable as an editor. Dr. Carstens shares in the credit for the good qualities of this thesis. However, any shortcomings remain solely my responsibility.

The other members of my thesis committee, Dr. Martha Balshem, Dr. Thomas Biolsi, and Dr. Leonard Cain, have also been very helpful with their suggestions and critiques of this thesis. Working with the Department of Anthropology at Portland State University has been a wonderful experience and I would like to thank the faculty for all of the opportunities they have given me.

I must also thank my wife, Irene, who has been there with me throughout this project and has patiently waited for me to finish along with our son, Alexander, who came into existence during the writing of this thesis. 
Finally, my sincere thanks go to Dr. T.P Paran and his wife, saroja. They opened their home to me during my stay in singapore and saroja helped me a great deal by introducing me to and teaching me the intricacies of the Malayalam language. I really enjoyed our weekly discussions, and I look forward to our next meeting. 
TABLE OF CONTENTS

PAGE

ACKNOWLEDGEMENTS ........................ iii

LIST OF TABLES......................... vi

CHAPTER

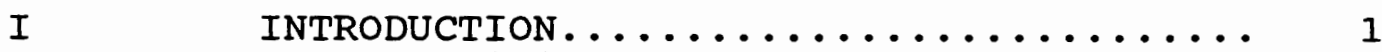

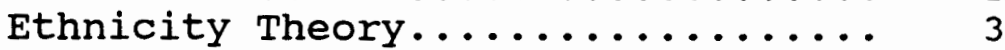

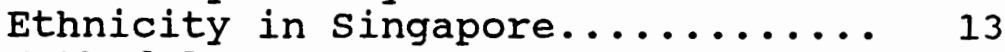

Methodology................... 19

II HISTORY: MIGRATION AND LABOR.......... 22

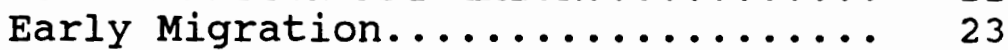

Twentieth Century Migration....... 24

III MALAYALEE GROUPS AND ASSOCIATIONS...... 30

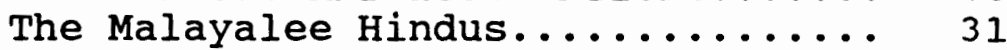

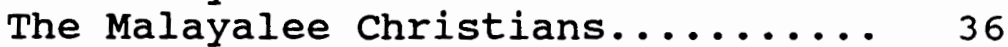

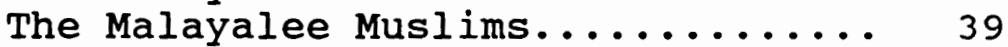

Malayalee Organizations.......... 40

IV MALAYALAM LANGUAGE IN SINGAPORE....... 48

V CONCLUSIONS................... 63

APPENDIX INTERVIEW QUESTIONS.............. 71

REFERENCES.............................. 74 


\section{LIST OF TABLES}

PAGE

\section{TABLE}

1 Membership in Singapore Malayalee

Associations, 1992................ 41

2 Knowledge of Malayalam in singapore by

Generation and Religion............. 53 
CHAPTER I

\section{INTRODUCTION}

The idea for this thesis came about while I was visiting my wife's family (who are singapore Malayalees) in singapore. One thing that caught my attention was that the word "we" referred to several types of group identities. It could mean Catholics, Malayalees, Indians, Singaporeans, or even Asians, depending upon the situation. Often the "we" referred to Malayalees as a group, yet they never seemed to come together as a group. Nevertheless, the Malayalee identity seemed just as important as the other identities in defining just who people are. This question of why the Malayalee identity remains so important led me on my quest to learn more about the entire Malayalee community.

During the past thirty years, ethnicity has become an increasingly important topic in anthropology and the other social sciences as anthropologists have attempted to understand culture(s) within the modern world system of nation-states. With the decline of the predominance of functionalist theory, we have seen that there are really no neatly bounded cultures, but rather peoples linked by crosscutting ties of ethnicity, region, religion, language, nation, etc. Even within a small nation-state such as 
Singapore, anthropological studies have focused on culture within any one of the above mentioned cross-cutting groupings, highlighting the complex ways in which the study of culture may be approached in any modern nation-state. For example, in Singapore, studies by Mani (1977) and Sinha (1987) have focused on Hindu caste and religion respectively: Menon (1976) focused on a particular ethnic neighborhood; Li (1989) has examined Malay culture and ethnicity; and Benjamin (1976) has looked at the overall development of a distinct singaporean culture, based upon the idea of multiracialism.

In this thesis I will examine ethnicity among the Malayalees, a relatively small ethnic group in singapore. The Malayalees, who are immigrants or descendants of immigrants from the state of Kerala in South India, make up the second largest group of Indians in Singapore after the Tamils. I will examine how Malayalee ethnicity has remained important despite cross-cutting identities, such as those mentioned above, and the overall Chinese-Malay-Indian organization of singapore.

In the study of Singapore Malayalee ethnicity it is important to make a distinction that has been made (c.f. Keesing 1975; Handelman 1977; Eriksen 1993) but is often ignored in ethnic studies: the difference between ethnic consciousness and an ethnic group. As a whole, the Singapore Malayalees would seem to be more of an ethnic 
category rather than an ethnic group. There is a definite ethnic consciousness among singapore Malayalees, but this does not necessarily mean participation in a unified ethnic group.

To best understand singapore Malayalee ethnicity it is necessary to examine the ethnic category as a whole, the various groups and groupings of people within the category of 'Malayalee' in Singapore, and how this ethnicity is perceived and expressed at the level of the individual. As will be shown in Chapter Three, the diversity of the various Malayalee groups in singapore means that being Malayalee may mean different things to different individuals, depending upon which groups they belong to and/or participate in. The level of the individual has all too often been ignored in ethnic studies. It is at the level of the individual where identities are formed, manipulated, and expressed (Bentley 1987:26). As will be shown in this thesis, ignoring the level of individual identity would mean ignoring a very large portion of the singapore Malayalee community, as many of them do not participate in any Malayalee groups.

\section{Ethnicity Theory}

There are four works that have been especially influential to my thinking about ethnicity in general, and ethnicity in Singapore in particular. Barth (1969), Nagata (1974), and Bentley (1987) have added significantly to ethnicity theory, while Benjamin (1976) has added 
considerable insight into the specific case of ethnicity in Singapore. While I do not discount the importance of other works on ethnicity, I feel that an understanding of these four works is most important in order to understand the structure and use of ethnicity in Singapore today.

Frederick Barth argues in his seminal early work on ethnicity, Ethnic Groups and Boundaries (1969), that ethnic groups are politically organized groups which exist only in relation to other ethnic groups and depend upon the maintenance of social boundaries between them. Ethnic groups emphasize particular cultural traits while ignoring others in order to demonstrate similarities among themselves while highlighting differences with others.

It is important to recognize that, by definition, an ethnic group is an organized entity. However, in the study of ethnicity and ethnic consciousness we do not always deal with such neatly organized groups, as the example of the Singapore Malayalees will show. The most useful part of Barth's work for my purposes is the emphasis on social boundaries and the cultural traits with which they are defined. Before anything else, ethnicity involves the definition of self and other, those who are somehow more like oneself and those who are not. Therefore no study of ethnicity can ignore how a group or category defines itself and remains separate from other groups or categories of the same order. 
The Singapore Malayalees are not politically organized as a whole, but they do have several organizations which can represent their interests if needed. They also use several cultural traits to distinguish themselves from others, such as language (both Malayalam and their proficiency in English), being highly educated, and the sharing of a common homeland in Kerala.

Nagata (1974) adds to Barth's analysis by showing that it is important to recognize that ethnic identities are often situationally defined and can be changed. A person may have more than one ethnic identity which can be emphasized at different times. For example, singapore Malayalees belong to the much larger Indian ethnic group. The Indian identity, rather than the Malayalee identity, is emphasized vis-a-vis the Chinese and Malays. The Malayalee identity, in fact, would not make sense in the same situation: it is an identity differentiated from within the Indian community but not always from without, just as most Indians would not normally differentiate, for example, between Hokkien, Hakka, and Cantonese Chinese.

other factors, such as religion, can also play an important role in determining who can claim a particular ethnic identity and who cannot. Nagata (1974) clearly shows how this works for Malays, Arabs, and Muslim Indians in Penang, Malaysia. She shows that, depending upon the situation, people are able to oscillate between these 
different ethnic identities through the use of a common Islamic identity. However, her example of the Chinese Muslims shows that religious identity does not necessarily overcome all ethnic boundaries.

Many of the identities available to the singapore Malayalees are situationally defined. For example, a Mar Thoma Syrian Christian' may emphasize that identity when meeting with an orthodox Syrian christian. She may emphasize a Syrian Christian identity vis-a-vis a Catholic, or perhaps a Christian identity with a Hindu or a Muslim, and so on: a Malayalee identity to a Tamil, South Indian to North Indian, Indian to Chinese or Malay, and Singaporean to Malaysian (or foreigner).

With the number of religious identities mentioned above, it is no surprise that these may also ally parts of the Malayalee community with other communities. Perhaps the best example of this is with the Malayalee (and Tamil) Muslims, who in many cases have close (marital) ties with the predominantly Muslim Malays more often than with other Malayalees who are not Muslims.

1 The Syrian Christians discussed in this text are Malayalee Christians from Kerala who claim descent from Brahmin converts of St. Thomas, who is said to have come to Kerala in $52 \mathrm{~A} . \mathrm{D}$. There are at least four different branches of syrian Christians, only two of which are represented by churches in Singapore: Orthodox Syrians and Mar Thoma Syrians. The difference between these two churches has been described to me as similar to that between Catholics and Protestants. For more complete descriptions of Syrian Christians in Singapore see Suja Thomas 1991, Mathew 1974, and Lu 1979. 
Benjamin (1976) argues that ethnicity (multiracialism) is an important part of Singaporean national culture. He also argues that the singapore model of multiracialism has led to a "cultural traditionalism" which "puts Chinese people under pressure to become more Chinese, Indians more Indian, and Malays more Malay" (1976:124). This is significant for this study because being "more Indian" will mean different things to different people. For example, the Tamils are the largest Indian category in singapore, comprising about sixty-three percent of the Indian population. Tamil is one of singapore's official languages and has been designated as the "mother tongue" for singapore Indians. 2 It has also been the only Indian language that could be studied in school. While being more Indian may mean speaking Tamil to the Tamils, this has not been so for other Singapore Indians. Many Malayalees, for example, have chosen to learn Malay as their second language ${ }^{3}$, while they must learn what they consider to be their own language, Malayalam, elsewhere, if they even learn it at all (Lu

2 Singapore's official languages are chinese (Mandarin), Malay, Tamil, and English. Malay is the official national language. However, English is the primary language of government, business, and education.

3 In singapore schools each student is required to study two languages. The first language is English and the second is supposed to be that student's "mother tongue". Ideally this has meant that chinese students would learn Mandarin as their second language, Malays would learn Malay, and Indians would learn Tamil. However, it is now possible for some Indians to choose to learn another Indian language as "mother tongue" (see Chapter Four). 
1979). To be more "Indian", Malayalees must be "more Malayalee".

But what exactly does it mean to be 'more Malayalee'? Again, it means something different to different segments of the population. For example, some may show their

'Malayaleeness' through speaking Malayalam whenever possible or through participating in particular Malayalee organizations. But others may seem not to show much 'Malayaleeness' at all, as is the case of many of the Malayalee Catholics, who have long been seen by other Malayalees as being much more 'Westernized' (Iu 1979). Perhaps the approach put forth by Bentley (1987) can give us the best insight into this question. In "Ethnicity and Practice", Bentley notes the inadequacies of two dominant approaches to the study of ethnicity: primordialist and instrumentalist. The primordialist model argues that people in changing social contexts group together based upon already existing cultural similarities. Ethnic groups then take care of people's emotional needs to be around others with similar dispositions and, secondarily, defend their collective economic and political interests if necessary. Good examples of this approach can be seen with Geertz (1973), who describes the conflict between primordial sentiments and nation building in the post colonial world, and Keyes (1976), who defines ethnicity as being primarily based upon the idea of shared descent and common cultural 
features such as language.

The instrumentalist model argues that ethnicity and the formation of ethnic groups are based upon shared material interests, from which shared sentiments arise. Barth (1969) and Nagata (1974) present two excellent examples of this model. Barth regards common cultural features as results of ethnic group formation rather than the reverse (1969:11-12). Nagata (1974) describes the oscillation of individuals between different ethnic groups as being due to interests, particular cultural traits being ignored or emphasized depending upon the situation.

In other words, ethnicity comes about when people in changed social circumstances, such as the nation building in post colonial Africa and Southeast Asia, group together based upon either 1) culture or 2) economic and political interests. Bentley argues that neither the primordialist nor the instrumentalist approach takes into account the recognized commonalities which tie together the members of an ethnic group:

...both leave unexamined the microprocesses by which collectivities of interest and sentiment come into existence $(1987: 26)$.

Bentley stresses the understanding of ethnicity at the level of the individual through Bourdieu's (1977) concept of habitus, that is, as one speaks a language without reference to any overt rules of structure, one also acts and reacts in 
the same manner with regard to culture. Habitus may be regarded as the underlying structure of culture and the basis for the strategies which people act upon and the way they think about the world. This idea applies to ethnicity in that people will tend to group together based upon shared habitus, while the 'other' will be defined by differences in habitus. It also applies to other types of identities, which helps to explain the congruence between and crosscutting of religious, ethnic, and national identities. Habitus also changes over time as people and societies change. Such is the case in intergenerational conflict. As different generations will be differentially adapted to any kind of changing situation, habitus will differ among those generations and ethnic symbols may take on different meanings to them (Bentley 1987:43).

In order to move beyond the primordialistinstrumentalist argument Bentley applies Bourdieu's (1977) theory of practice, which argues that people not only base their actions on existing structures, in this case those of ethnicity and ethnic groups, but they are also active agents in creating and changing these structures. Ethnicity involves more than just the instrumental manipulation of culture or a basis of primordial feelings. People grow and learn to operate under invisible cultural parameters, that is, they learn what kinds of strategies are and are not possible within any particular cultural milieu. As people 
work within particular social structures they also change them, although not necessarily knowing that they are doing so. As structures change over time, people will tend to define self and other based on perceived similarities and differences in habitus.

This approach will be very useful in understanding Malayalee ethnicity in singapore, as both the primordialist and instrumentalist approaches could be used, but neither alone could take into account the whole situation. For example, the primordialist approach might emphasize the facts that the singapore Malayalees share primordial sentiments in their origination from the Indian state of Kerala and share a common language in Malayalam. Although not all of them speak it, they all consider it to be their language. But why, then, do so many Malayalees not participate, or even have any interest in singapore Malayalee organizations?

Using the instrumentalist approach one might emphasize the fact that the Malayalees have historically been a middle-class minority in Southeast Asia, more likely to be educated in English and employed in more clerical-type jobs, while the Tamils, the Indian majority in singapore, came to the Malay Peninsula primarily as manual laborers, e.g. working in the rubber plantations under the British (Sandhu 1969, Arasaratnam 1970). Therefore the Malayalees have historical economic reasons for differentiating themselves 
from the Tamils. One might also emphasize the fact that the Singapore government has actively pushed for the multiracialism and multiculturalism on which singaporean national culture is based (Benjamin 1976), and this in turn has reinforced the need for the smaller ethnic groups to retain and emphasize their ethnic identities.

But neither of these approaches can account for the feelings of alienation or anomie from their own culture that many Singapore Malayalees have. These feelings of alienation can be seen as coming from a core contradiction in Malayalee culture in particular and singapore culture in general. It can be explained as resulting from differences in habitus among individuals as the social structures of Singapore have changed over the years. The first generation of Malayalees came as sojourners and eventually settled down as citizens. The second generation has grown up in Singapore as citizens. Both generations have had to deal with what it means to be Malayalee in singapore: as a historically relatively well-off minority due to their education, familiarity with the English language and contacts with the British, yet a minority whose language and culture are felt to be slowly disappearing from the Singapore scene.

Bentley's approach starts at the level of the individual and examines how differing habitus may be manifested through individual actions. The level of the 
individual is important because that is where habitus exists: in how individuals think about and act upon the world around them. Using the theory of practice and the concept of habitus he is able to show how ethnic sentiments of commonality come into being and are powerful forces (which are nevertheless manipulated) in people's lives. Using this method we will be able to approach the feelings of Malayalee identity and alienation from Malayalee culture that often go hand in hand with being a singapore Malayalee. In singapore, habitus is shared among people in many different ways: among religious groupings, different generations, ethnic groups and categories, and, as Benjamin (1976) has shown, all singaporeans. Bentley's approach is able to account for all of these variables, any one of which ignored would severely limit our understanding of singapore ethnicity.

\section{Ethnicity in singapore}

In any of the literature on singapore, not only in academic works but in tourist guides and other descriptions, one fact is inevitably stressed: singapore is a multiracial, multicultural society. The main groups in this multicultural society of 2.6 million are the chinese (76\%), Malays (15\%), and Indians (7\%). There is also a fourth category known simply as 'other', which consists of anyone not in the previous three categories, such as Eurasians and Europeans. 
To be Singaporean, one must be Chinese, Malay, Indian, or other. This institutionalized ethnicity, or 'multiracialism' as it is known in singapore, as Benjamin (1976) has shown, is actually a key element in singaporean national culture. This can be seen, for example, in the fact that the first thing one singaporean wants to know about another is whether that person is Chinese, Malay, or Indian. It is, in fact, everywhere in singapore life: marked on each individual's national identification card; in the respective locally produced Chinese, Malay, and Indian serials shown on television; and in the respective official languages which are supposed to correspond to each group.

Closer inspection reveals that these ethnic groups are by no means homogeneous. The chinese are made up of a variety of 'dialect' groups, such as Hokkien, Cantonese, and Teochew. The Malays come from a variety of places in Indonesia and Malaysia, and include not only 'true' Malays, but other groups such as Javanese and Bugis as well. The Indians also contain a wide variety of groups: South Indians such as Tamils, Malayalees, and Telugus; North Indians such as Punjabis, Gujeratis, and Bengalis; and 'Indians' from places that are now not India at all such as Sri Lankans and Pakistanis.

Given the above, it is interesting that the boundaries between the different categories of singapore Indians have not eroded, while they may have, at least to some degree, 
among the Chinese and Malays due to Chinese language (e.g. the government's speak Mandarin campaign and written Chinese) and Islamic religion respectively. But there is no such common organizing factor for the Indians, as they differ in language, religion, region, and even nation of origin. Caste has been mentioned as one possible organizing factor among the Indians, but it has also been pointed out as being extremely problematic in a secular nation which stresses "meritocratic egalitarianism" (Benjamin 1976:127). Although these smaller groups are overshadowed by the larger Chinese-Malay-Indian organization, they have not blended together in a 'melting pot' and they in fact continue to thrive today.

According to the 1990 census there are 16,329 Malayalees in singapore. They are the second largest Indian group in singapore following the Tamils, who make up about sixty-four percent of the singapore Indians. The Malayalees make up roughly eight and one-half percent of the Indian community, which is about seven percent of singapore's entire population.

The Malayalees themselves are a diverse community, with a number of other, non-ethnic, identities which can be, and often are, emphasized along with the Malayalee identity. There are three main religious groupings: Hindus, Christians, and Muslims. Furthermore, the Hindus come from different caste backgrounds, most notably Nairs and Ezhavas; 
the Christians divide into three main groupings: Catholics, Mar Thoma Syrian Christians, and orthodox Syrian Christians; and the Muslims, although not differed by sect, differentiate between Malabar Muslims (Northern Kerala) and Travancore Muslims (Southern Kerala).

Following the above discussion it is now necessary to explicate what I mean when using the term 'ethnicity'. First, ethnicity is a particular type of identity. As Bentley (1987:27) aptly states: "At base ethnicity involves a claim to be a particular kind of person." It involves the claim to be the member of some primordial group or category, however fictional the charter of that group or category may be. Ethnicity, as with other types of identity, involves the distinction of cultural categories: cultural categories which unite and divide similar and different kinds of peoples. Ethnicity is distinct from other types of identities, such as religious or national identities, although at times these identities may covary or crosscut each other. For example, in Singapore and Malaysia to be Malay means one is Muslim. But this covariance of identities does not preclude the need to distinguish between Malays and Indian Muslims. The Muslim part of the Malay identity is shared with other Muslims. However, the Malay identity is not shared with other Muslims (although people may switch ethnic identities the distinction remains, c.f. Nagata 1974). In Singapore there is a category of persons 
who recognize themselves as Malayalees. They are subdivided by religious identities which crosscut other ethnic categories. And they all share a national identity: Singaporean.

Secondly, one may be conscious of one's ethnicity (i.e. belong to a particular ethnic category), yet not necessarily participate in activities of an ethnic group. This is very often the case among Singapore Malayalees (see Chapter Four). Although the majority of Singapore Malayalees have little or nothing to do with any kind of ethnic organization, their ethnic identity remains an important part of their lives as a means of defining self and other. Third, by the necessity of differentiation between self, those like oneself, and others, ethnicity involves the creation and maintenance of social boundaries within which one can claim that identity. These boundaries are maintained through the manipulation of cultural symbols such as language and dress (c.f. Barth 1969). These boundaries are, however, fluid and people may oscillate between categories depending upon the situation (c.f. Nagata 1974). There may also be differing levels of ethnicity where one ethnic identity may encompass several smaller identities. This has happened in singapore where the three larger ethnic identities-- Chinese, Malay, and Indian-- all include several ethnic subdivisions, such as the Tamils, Malayalees, Punjabis, etc., who share the Indian identity. These may be 
thought of as Indian subgroupings, however their identities are no less ethnic than the Indian identity; each group claims a common homeland and ancestry. It is also significant that each of these groups has its own native language (c.f. Keyes 1976), a claim which the category Indians cannot make.

Finally, ethnicity must be understood in terms of nationalism and national and regional history. A look through the literature on ethnicity shows that it has taken on different forms in different regions. For example, the ideal of the cultural 'melting pot' and the existence of many kinds of 'hyphenated Americans' shows ethnicity in the United states to be much different from that in singapore (and Malaysia or Indonesia for that matter) where there is an ideal of multiculturalism and 'unity through diversity'. And the crosscutting of identities available to Singapore Malayalees will obviously be different from those available to Malayalees in Kerala. Ethnicity formation is a historical process, a process which cannot be ignored if ethnicity is to be understood properly.

This thesis examines the Malayalee community as a whole, although I realize that there could easily be enough material to do a complete ethnography on any one of the segments of the Malayalee community (e.g. Lu 1979; Mathew 1974; Thomas 1991). Only in examining the community as a whole will we be able to get at the significance of being 
Malayalee in singapore.

In the second chapter of this thesis I briefly discuss the history of how and why most Malayalees came to be in Singapore. Chapter Three examines the organization of the Malayalee community and how Malayalee organizations are used in the expression of Malayalee ethnicity. In Chapter Four I look at the Malayalam language as a key symbol of Malayalee ethnicity and discuss its relationship with the feelings of alienation expressed by many Singapore Malayalees. Finally, in the fifth chapter I discuss in more detail how the theory of practice and the concept of habitus help us to better understand those aspects of Malayalee ethnicity discussed in the previous chapters.

\section{Methodology}

Five previous studies have dealt with the singapore Malayalees: Sara Thomas (1956), Mathew (1974), Menon (1976), Lu (1979), and Suja Thomas (1991); all unpublished B. A. Honors Theses at the National University of Singapore's Department of Sociology and Anthropology. of these studies only Sara Thomas (1956) examined the Malayalee community as a whole and, of course, much has changed since then. Of the other studies Mathew (1974), Iu (1979), and Suja Thomas (1989) focus on Malayalee Christians, the Syrian Christians more specifically, while Menon (1976) examines a 'neighborhood' (the Sembawang Naval Base) formerly dominated by the Malayalees. 
The fieldwork for this thesis was done over an eight month period in Singapore, from January to August 1992, during which time I was a visiting associate at the Institute of Southeast Asian Studies. The data for this project were collected primarily through interviews with thirty informants and countless discussions with as many others as I could meet (75-100 Malayalees in all). I also observed as many Malayalee events and gatherings as I could, such as the events held by the various singapore Malayalee associations.

The setting for the interviews, all conducted in English, tended to be informal, most often taking place at the informant's home or at a nearby coffee shop. But situations ranged from those where I was able to use a tape recorder to those where I was not able to take notes at all due to the social situation or the informant feeling uncomfortable with it. After the latter situation I would, of course, write the notes as soon as possible. The interviews were based on a set of questions which I had formulated before entering the field (see Appendix). I used these questions as much as possible. However, I felt it important to let the informants dictate the pace and direction of the interview to a certain extent in order to bring out what was important to them.

Two situations in particular facilitated my gaining contacts within the Malayalee community. My wife is a 
Singapore Malayalee, so I was able to make some contacts which I would not otherwise have been able to, mainly through her family members and neighborhood friends. I also studied the Malayalam language while in Singapore. This fact in particular interested people in me and my project and it gave them an interest in talking to me. I was very fortunate in never being turned down for a short talk or even an interview and I would like to thank all those who helped for their generous hospitality. 
CHAPTER II

\section{HISTORY: MIGRATION AND LABOR}

Malayalee migration to singapore is best understood when seen in relation to the overall pattern of Indian migration to Malaya in the colonial era. The vast majority of Indian migrants to Malaya were Tamils, recruited by the British to work on the rubber plantations under the indentured labor and kangani systems.' In comparison, the Malayalees who migrated to Malaya and singapore were, for the most part, unassisted. Although there were some working-class laborers among them, most notably in the shipyard and construction industries, the majority of Malayalees migrated to Malaya and singapore to work as clerks, shopkeepers, or in the professions (Arasaratnam 1970:44; Sandhu 1969:123).

This pattern of movement of labor from south India to Malaya was facilitated by three main factors. First, the use of the indentured labor and kangani systems were limited

1 Under the Kangani system the Kangani was a laborer, usually a Tamil, who was put in charge of the other laborers. He was also used to recruit other laborers from India, usually from his own village or district. His comparative gave compelling reasons for others to follow him. The laborers would then enter into contracts (usually verbal) with rubber estate employers which could (in theory) be terminated with one month's notice by either party. See Sandhu 1969:89-193; Jain 1970. 
to Madras state (now Tamil Nadu) in South India. This is why the vast majority of the workers in the labor-intensive plantations were Tamils. Secondly, South India (and ceylon) had already been under British administration, as were the Straits Settlements of singapore, Malacca, and Penang, so many South Indians were already familiar with working under the British system. For example, many of the British administrators in Malaya recruited ceylonese staff who had worked for them before in ceylon, or who were recommended by officers who had worked in Ceylon (Arasaratnam 1970:33). Finally, it is significant that the Malayalees were (and still are) "the most literate linguistic group in India" (Arasaratnam 1970:34). The educational systems in the states of Travancore, Cochin, and Malabar (which now make up the state of Kerala) and their familiarity with the English language enabled the Malayalees to flourish in the clerical field, which can be seen in their dominance in jobs on the British naval and air force bases in singapore. ${ }^{2}$

\section{Early Migration}

Very little has been written about the early history of Malayalees in singapore. In fact the only mention of Malayalees in pre-British Malaya (i.e. pre-1789) is of traders and merchants from Malabar who either sailed their own ships or sent goods with the Portuguese, who controlled

2 For a more in-depth discussion of Malayalee literacy in Kerala see Jeffrey 1987. 
the trade routes at the time (Bassett 1964:122; Sandhu $1969: 180)$.

In June 1819 Sir Thomas Raffles landed in Singapore for the second time. In his entourage was Naraina Pillai, a Hindu trader from Penang. Pillai stayed on in singapore working as a clerk, then went on to start a brick-making business supplying the emerging city. He eventually became a very successful businessman and is credited with being a leader in the building of modern singapore (Netto 1961:14). Pillai is also credited with founding the first Hindu temple in singapore, which was built by Indian convict labor. 3 It is interesting that Pillai is a common Malayalee Hindu name, but many Tamils also share this name. Therefore, Pillai is a historical figure who can be claimed by both communities. In the books in which Pillai is referred to (Netto 1961; Sandhu 1969; Turnbull 1972,1989) his background is not mentioned except that he was a Hindu trader from Penang. Several of my informants claimed that Naraina Pillai was a Malayalee, thus asserting the significance of Malayalees in early singapore history.

Twentieth Century Migration

I have found no records of the numbers of Malayalees in singapore in the early part of the twentieth century, but

3 singapore was used as a penal colony for Indian convicts until 1860. For a detailed discussion see Sandhu 1969:132-140. 
we do know that there were a significant number of Malayalees in singapore in the early part of this century as the Singapore Kerala Association was founded in 1917. By 1921 there were 17,190 Malayalees in the whole of Malaya, or about 3.7 percent of the Indian population (Arasaratnam 1970:48). The Malayalee population tended to concentrate in the cities, especially in Southern Malaya and Singapore. This contrasted with the large numbers of Tamils working on the plantations (Arasaratnam 1970:46; Sandhu 1969:239).

Arasaratnam (1970:44) notes that the Malayalee community, the second largest Indian community in Malaya after the Tamils, was composed of two sectors during the British control of Malaya and Singapore in the twentieth century. First were the working class people who tended to work at the docks, most notably the Sembawang Naval Base, which was considered to be a Malayalee area; in industrial labor; and at the plantations. Unfortunately there is little mention of these working class people in the literature on the history of Indians in Malaya and Singapore. The focus on the historical importance of the Malayalees in Malaya and Singapore tends to be on Arasaratnam's second category, the Malayalee middle class people in the professional and clerical fields in the British military, the government, and private firms.

The first successful group in the professions and clerical fields, primarily working for the British, were the 
Ceylon Tamils who came in large numbers in the $1890^{\prime} \mathrm{s}$ (Arasaratnam 1970:33; Rajakrishnan 1988). They had worked for the British in ceylon and were familiar with their system, and it is significant that they had been educated in English.

The second wave of immigration to fill these types of jobs came primarily in the 1920's from India itself, and primarily from the Malayalees from what is now the state of Kerala. They left their homeland as sojourners to follow good job opportunities. ${ }^{4}$ Educated Malayalee men migrated to Malaya and singapore and proceeded to dominate in several fields:

Once they had established a bridgehead in Malaya, they rapidly extended their field of endeavour; in addition to monopolizing almost the whole of the civilian clerical and junior officer grades of the British War Department's installations in Malaya by the 1930's, they had very largely succeeded in supplanting the Ceylon and Madras Tamil conductors, clerks and assistants on the European-owned rubber, oil palm and other plantations (Sandhu 1969:123).

With the Malayalees, as with the Ceylon Tamils earlier, once they had a "foot in the door" they brought their family members and friends to fill other needed jobs, and as there

4 There is no mention of unemployment problems in Travancore, Cochin, or Malabar-- the three former states which now make up the state of Kerala-- at this time by Sandhu (1969) or Arasaratnam (1970). However, unemployment in Kerala was often mentioned as a factor in migration by my informants in singapore. But most of them came to singapore after World War Two and none were alive in Kerala in the $1920^{\prime} \mathrm{s}$. 
was early success and a large number and variety of clerical type jobs available, more immigrants were encouraged (Arasaratnam 1970:34).

The next and most important period of Malayalee migration to singapore came during the period immediately following world War Two (1946-1953). In fact, most of my informants reported that they or their families had come to Singapore during this period. As the British regained control of the area following the war, singapore experienced very rapid growth and there was a "substantial Malayalee middle-class intake" (Arasaratnam 1970:41).

The story of one informant, Mr. Matthew, a syrian Christian, is an excellent example of how and why many Malayalees migrated to singapore during the early post world War Two period. In the early 1950's Mr. Matthew was a young man living in Travancore, in the South of Kerala. He graduated with a bachelor's degree and was working at his first job, teaching part-time at a school. He had heard of the job opportunities in singapore, but he enjoyed his job and had no desire to go to singapore. However, his uncle had different ideas; he thought that it would be best for his nephews to go where the best job opportunities were. Singapore was a rapidly growing city and his nephews would be able to make much more money there than they would be able to at similar jobs at home in Travancore. Also, as some of my informants have told me, there was at that time 
(and still is today) an unemployment problem in Kerala. Mr. Matthew found out in 1952 that he had to go because his uncle had already purchased a ticket for him on a boat from Madras to singapore. He, along with his two brothers, set off for singapore where he worked as a teacher and administrator for over thirty years. He returned to Kerala after a few years to get married and brought his bride back to singapore where they settled down, raised two children, and all eventually became singapore citizens.

Such a story of a Malayalee's migration to singapore is not at all atypical. Most went to singapore merely as sojourners, to make some money and eventually return home. In fact Turnbull (1989:96) notes that the Indians were more transient than even the Chinese, and the Malayalees have been noted as having the closest ties with "their motherland" (Sandhu 1969:240). This can also be seen in the fact that most of those Malayalees who migrated to singapore before World War Two eventually returned to Kerala (Thomas $1956: 29)$.

The flow of Malayalees to Malaya and Singapore was for the most part stopped with the passing of the Immigration Ordinance (No. 68 of 1952 ; Prohibition of Entry) by the Malayan government in 1952 and its enactment on the First of August, 1953. This law basically restricted immigration to those who were immediate family members of those already in Malaya, those who had special occupational skills, or those 
who were employed by or owned a substantial, wellestablished company (Sandhu 1969:149-150).

The Malayalees were in no way restricted to any part of Singapore at this time, but there were a few areas where there tended to be many Malayalees. The most prominent of these were the British bases, such as the Naval Base at Sembawang and the Royal Air Force base at Seletar. However, all of this changed after singapore achieved full independence in 1965 and took control of the bases from the British in 1972. At this point many of the Malayalees returned to Kerala or migrated elsewhere, especially those from the bases. The Malayalees had enjoyed a good relationship with the British and they were not sure of the relationship with the new singapore government (Menon 1976). Nevertheless, many Malayalees also found it advantageous to stay in singapore. They found it a relatively safe place to raise their children, where they could also make a comfortable living, something which may not be so easy in Kerala, although they looked on Kerala as a beautiful place and their homeland. 


\section{MALAYALEE GROUPS AND ASSOCIATIONS}

The Singapore Malayalees recognize themselves as being comprised of three main religious groupings: Hindus, Christians, and Muslims. In this chapter I will discuss the organization of the Malayalee community based upon these groupings and the other organizations important to the community. I will examine the basic organization of the Malayalee community and how organizations are used for the expression of Malayalee ethnicity. It will also be shown that a very large number of Singapore Malayalees actually have very little or nothing to do with these organizations. Therefore it would seem that many Singapore Malayalees do not feel a need to express their Malayaleeness in groups. But again, this does not preclude the ethnic consciousness, the consciousness of being Malayalee, which will be further discussed in the next chapter.

Although I refer to them as a community, the Malayalees are not a community in the formal sense, that is a group of people living or working together sharing at least some part of their daily lives. But as an ethnic group (or category) they do fit Anderson's definition of an 'imagined community' (as do all ethnic groups), that is members do not know, 
meet, or even hear of most other members, yet each member knows that he or she is part of a much larger group of people sharing particular commonalities (1983:15). The Malayalees do not occupy any particular part of Singapore, rather they are spread out over the whole island. There are a few areas in which Malayalees are more common than in others, such as Yishun, Sembawang, Seletar, and Ang Mo Kio. This is due to the proximity of these areas to areas which were formerly dominated by Malayalees, such as the sembawang Naval Base and the Air Force Base at Seletar.

\section{The Malayalee Hindus}

There are no data on the actual numbers or percentage of the Malayalee population which is Hindu, but there is agreement among my informants and other authors (c.f. Menon 1976:57) that the Hindus make up the largest portion of the Singapore Malayalees. As mentioned above, the Malayalee Hindus in singapore come from two main castes, Nair and Ezhava (c.f. Menon 1976:22,28; Sara Thomas 1956:33). But caste is not much of an issue here; there are no Malayalee caste organizations and the community is in no way organized by caste. ${ }^{1}$ That is not to say that caste does not affect

1 Although there are no real caste associations, the organizations based on the followings of Sri Narayana Guru, i.e. the Narayana Mission and the Guru Kulam (see below) have had memberships made up of mainly Ezhavas (Menon 1976:228; Sara Thomas 1956:133). Sri Narayana Guru was himself an Ezhava, which was considered to be one of the lower castes in Kerala. 
whom some individuals associate with, especially among the older generation, but as an overall factor in the community, its effect is severely diminished because of the fact that living in singapore among an overwhelming majority of nonIndians and non-Hindus and being spread out over the whole island has limited the role caste can play in daily life (Benjamin 1976). Most of the older Malayalees have also made a conscious effort to downplay caste differences, usually citing a 'more modern' way of life and thinking in Singapore as compared to India or the following of Gandhian ideals. Younger Malayalees, having grown up in singapore, know little or nothing about caste and regard it as a rather useless and outdated system.

Unlike the Syrian Christians or the Malabar Muslims (see below) the Malayalee Hindus have no one place to call their own where they worship. This is due to the nature of Hinduism itself, where one offers pujas (worship) to whichever particular deities and temples that person finds to be efficacious rather than attending any one particular congregation. Much of the worship is done at home at an altar or prayer room (Sinha 1987). Therefore Malayalee Hindus never really come together as a whole group. Instead they attend the various temples around the island along with all the other Hindus. There are a couple of temples which are mentioned by informants as being particularly popular among Malayalees, such as the Krishna Temple at waterloo 
Street (Sinha 1987:51), Krishna being a popular deity in Kerala, and a temple in the Toa Payoh area where the Malayalee Hindu Samajam (association) has had an Aiyyappan deity installed. Aiyyappan is considered to be a Malayalee deity and is very common in Kerala.

The Aiyyappan deity sits in a small shrine off to the side of the main temple, which is dedicated to a deity (Kaliamman) more familiar to Tamils. The Malayalee Hindu Samajam holds four different monthly pujas at the Kaliamman Temple, but there does not seem to be anything particularly "Malayalee" about these pujas as they are open to all Hindus and they are done with the appropriate sanskrit prayers. Even the Aiyyappan shrine itself has Tamil script on it, but no Malayalam script. However, the first time I went to this temple I was told by one Tamil man (pointing to the side of the temple where the Aiyyappan shrine is): "The Malayalees pray over there."

The Malayalee Hindu Samajam (MHS), the only formal (i.e. registered with the government) Malayalee Hindu organization in singapore, was founded in 1926 with the goal of helping destitute Malayalee Hindus, mainly those who died in singapore and would not otherwise be given a proper Hindu burial. They also made the appropriate arrangements with the deceased's family in India, such as transferring his savings back to India. But as the Malayalee Hindu population changed from transient to resident over the 
years, the same functions were no longer needed. Instead, as one informant expressed:

At the same time we found that the Malayalee boys and girls, because the parents were so busy making money and looking after their welfare (rather) than teaching....they started neglecting the cultural/religious side of 1 ife.

The MHS has taken on the task of bringing the Aiyyappan deity from Kerala and installing it in the Kaliamman Temple. In sponsoring the monthly pujas they attempt to promote their religion and culture, among their young people especially, in a place where there are many other religious and cultural options for people to choose from. The MHS also attempts to keep some semblance of a group among the Malayalee Hindus, who might not otherwise come together as a group. The pujas are a good example of this, especially the yearly puja held in January when an estimated one thousand people attend. But it must be remembered that these are 'Hindu' events more than 'Malayalee' events and not only Malayalees attend even though, as mentioned above, Aiyyappan is considered to be a Malayalee deity.

There are also two other Malayalee Hindu groups, the Narayana Mission and the Guru Kulam, although they might not actually identify themselves as such due to their following of the teachings of sri Narayana Guru, a philosopher and religious reformer of the early twentieth century in what is now the state of Kerala. The basic philosophy of sri 
Narayana Guru is usually quoted as being "one caste, one religion, one God for mankind" (Menon 1976:27). His ideals were the unification of mankind and the end of discrimination through the breaking down of barriers set up by caste and religion.

The Narayana Mission is registered with the government as a charitable organization rather than as a Malayalee or religious organization, but most Malayalees still list it as a Malayalee (and primarily Hindu) organization. The Narayana Mission is basically a charitable organization set up by a group of Malayalee followers of Sri Narayana Guru in 1948, based in the Sembawang Naval Base area where there was formerly a very large Malayalee community. Their main activity now is their Home for the Aged Sick which they started in 1979. Their other activities include food relief and financial assistance to needy families and scholarships to needy students. They also hold weekly pujas to Narayana Guru and hold a yearly celebration of his birthday with several pujas, recitations of his works, and a cultural variety show (similar to that which is described below). The Narayana Mission has a membership of about three hundred, ninety percent of whom are Malayalees. In 1992 the Home for the Aged sick had one hundred and ten residents, seventy percent of whom were chinese and twenty-eight percent Indian. They are also a member of the community Chest of Singapore as a charitable organization. They 
differ from most other Malayalee organizations in that they promote primarily charitable programs rather than Malayalee culture and language, and membership is open to all Singaporeans.

The Guru Kulam is an informal (i.e. not registered with the government) organization also based in the Naval Base area. The main function of the Guru Kulam (literally "teacher's place") is as a place to study. For example, when I was there a group of six to ten young men met every Sunday to study Indian philosophy, such as the Upanishads and the philosophy of Sri Narayana Guru. The Guru Kulam also started offering classes in Malayalam in July of 1992. They began with six students between the ages of five and eight (five boys and one girl) and eight students in their teens and twenties (six male and two female).

\section{The Malayalee Christians}

After the Hindus, the next largest grouping is the Malayalee Christians. Among the Malayalee Christians there are three main groupings: Catholics, orthodox Syrian Christians, and Mar Thoma Syrian Christians. The Malayalee Catholics are by far the largest in number, although the exact number is very difficult to estimate. However, one of my informants, an elder in the community, estimates around five hundred Malayalee Catholic families in Singapore. They also do not have a meeting place as a whole group, but attend their respective local parishes around the island. 
The Malayalee Catholics are often perceived by other Malayalees and themselves as being more 'westernized' or 'modernized' as compared to the more 'traditional' other groups, such as the Syrian Christians. For example, the fact that fewer Malayalee Catholics speak Malayalam, especially among the younger generations, is duly noted by the Malayalee Catholics themselves and other Malayalees. This perception also has a historical reasoning, however. Malayalee Catholic women have long worn dresses, whereas other Malayalee women have stayed with the more traditional saris and the now popular Punjabi suits. This can be seen, for example, in several of the Malayalee Catholic women I talked to referring to themselves as Chatakaris, meaning one who is 'westernized', but in Malayalam literally meaning 'a woman who wears dresses'. I was also shown a photograph by one Catholic family who have been in singapore since the 1920's of a group of Catholic Malayalees in Singapore during the 1930's. In the photograph all of the women are wearing dresses. In more recent years, however, some Malayalee Catholic women have started wearing saris outside the home, such as when going to church, to express a more Indian identity.

There are approximately two hundred and fifty orthodox Syrian Christians and four hundred and forty-two Mar Thoma 
Syrian Christians in Singapore. ${ }^{2}$ Unlike those discussed above, the orthodox Syrian Christians and the Mar Thoma Syrian Christians each have their own meeting places, the respective churches where the groups gather each week. Unlike the other Malayalee groups, the Syrian Christian churches are Malayalee churches, and consist of nearly all Malayalee members. Each week these groups gather together for worship and fellowship, and they are also able to gather together for life-cycle events such as weddings and funerals. Both churches have taken to alternating English and Malayalam services every other week to keep the interest of younger members who may not know Malayalam very well.

The Mar Thomites have endured a recent hardship, as their property was needed by the government for a freeway extension. They were paid about $s \$ 800,000$ for their church and now meet at the Mar Thoma school on the other side of singapore. They are raising money to build a chapel on that site (they must set up and put back the chairs, etc. every week as they cannot leave things set up in the school's main hall), and eventually to acquire new property on which to build a new church.

2 The numbers on the population of both Syrian Christian groups were gathered by suja Thomas for her Bachelor's Honors Thesis (1991). As a Syrian Christian she had easier access to the membership lists than an outsider would have. Yet the task was not easy. Membership in the churches is listed by the male head of the family only. Therefore it took her many hours and help from other community members to figure out just how many members were in each family. 
The Malayalee Muslims

The Malayalee Muslims comprise the smallest of the three main Malayalee religious groupings. The Malabar Muslims also have their own meeting place, the Malabar Mosque. At this Mosque the Imam is a Malayalee from Malabar in Kerala. Although the Mosque, like all Mosques, is open to all Muslims, and in fact a wide variety of Muslims can be seen praying at this Mosque on Fridays, there is also an association, the Malabar Muslim Jama'ath, which meets at and takes care of the Mosque. Membership to the Jama'ath is exclusive to Malabar Muslims.

There are few Travancore Muslims in Singapore. They differ from the Malabar Muslims only in that they come from the South of Kerala, Travancore, while the Malabar Muslims come from Malabar in the North. There is no Travancore Muslim organization now, although there was at some time in the past.

Based on this brief description of these main Malayalee groupings it would seem that neither the primordialist nor instrumentalist modes of thought would adequately account for Malayalee ethnicity in singapore. Either approach might be able to account for the significance of identity among the Syrian Christians or the Malabar Muslims which are active and corporate groups, whether it is due to the basic sharing of religion, language, and homeland or common interests in mutual cooperation, occupational familiarity 
(e.g. many of the syrian Christians are middle class civil servants and clerical workers), and corporate landholding. But what about the much larger numbers of Malayalee Catholics and Hindus who do not come together in a group nor have any corporate holdings? Before attempting to address this issue it is necessary to take a look at the more secular official Malayalee organizations in Singapore.

\section{Malayalee organizations}

There are four other Malayalee organizations which do not belong to any specific religious group and which concentrate on, more so than any of the groups discussed above, the promotion of Malayalee culture and language: the Singapore Kerala Association (SKA), the Singapore Kairalee Kala Nilayam (Kerala Arts Center - SKKN), the Naval Base Kerala Library (NBKL), and the Udaya Library (UL). The SKA is the oldest and largest of these organizations, founded in 1917 and with about five hundred members now (see Table 1). The other three organizations were founded, not surprisingly, in the mid to late 1950's just after the large influx of Malayalees to singapore. These organizations have served important functions in the Malayalee community, especially during the period from the mid-1950's to the early $1970^{\prime} \mathrm{s}$. This was the period when the largest numbers of Malayalees were living in singapore and many lived as communities in specific areas. This was especially true of the British military bases, such as the 


\section{Table 1}

Membership in Singapore Malayalee Associations, $1992 .{ }^{3}$

$\begin{array}{lr}\text { Association (year founded) } & \text { Members } \\ \text { Singapore Kerala Assoc. (1917) } & 500 \\ \text { Malayalee Hindu Samajam (1926) } & 200 \\ \text { Malabar Muslim Jama'ath (1927) } & 400 \\ \text { Sri Narayana Mission (1948) } & 300 \\ \text { Naval Base Kerala Library (1954) } & 50 \\ \text { Singapore Kairalee Kala Nilayam (1955) } & 100 \\ \text { Udaya Library (1958) } & 86\end{array}$

naval base at Sembawang which was known as 'Little Kerala' (Menon 1976). The changes came about in the early 1970's due to the British military withdrawal, the subsequent departure of many Malayalees for Kerala or Britain, and the dispersal of the communities to housing projects throughout the island (see Chapter Two).

The organizations were important centers for learning

3 These numbers were given to me by officials of each organization, usually the president or head of the organization. Some of these numbers have also been listed in some of the programs published by the organizations for their various events. The NBKL gave me the figure of fifty active members, adding that many others help out, while other organizations gave figures of total members, all not necessarily active. 
and entertainment for the large numbers of Malayalees living in singapore at the time. For example, the children were able to learn Malayalam at each of these organizations, and the SKA, NBKL, and UL each kept libraries of books in both Malayalam and English and were community meeting and leisure centers. The SKA in fact had several branches around the island (which have since merged together) to serve each local community, and the NBKL and UL served the sembawang and Bukit Timah areas respectively.

The primary functions of these organizations at present is the promotion of Malayalee culture and language through the production of Malayalam stage dramas and cultural shows, such as the "Onam Night(s)" (see below) put on by the SKA and KNBL. There are many such events throughout the year produced by these organizations, 4 including productions of plays and talent contests (especially by SKKN), all of which are usually sell-outs in the various city auditoriums. But the biggest events of the year are the onam shows put on separately by SKA and KNBL.

These shows typically include the singing of popular

4 The UL has all but ceased to produce any such events over the past few years due to disorganization and uncertainty about their future (although they did manage to produce one short play for a drama competition including three other Malayalee organizations in 1992). This has come about because few people, if any, use their books anymore, and they have lost a permanent place in which to store their books. They had been told they would have to move from their present location, although no deadline had been given for their departure and they had not yet moved as of August 1992. 
Malayalam film songs by local Malayalee singers; dances performed by local Malayalee and other Indian dancers (and occasionally dancers brought in from Kerala); and dramas usually written and performed by Singapore Malayalee artists. This is typically the re-creation of culture which is represented in singapore cultural shows. Benjamin (1976:122) describes these shows as:

...bringing about a marked degree of cultural
involution in Singapore, in which each 'culture'
turns in on itself in a cannibalistic manner,
struggling to bring forth further manifestations
of its distinctivenes... 'culture' is used more
and more to refer only to the sort of projective
fantasies that can be performed on a stage or
written in books, and less and less to the
patterns that lie behind the contemporary
everyday life of ordinary singaporeans.

In other words, people are able to view, or even participate in, what they think of as their own culture, something that is thought of as missing from everyday life in singapore. It is to these shows that many Malayalees come to reaffirm their Malayalee identity in viewing that part of their culture which is similar to all of them and distinct from all others in Singapore: that is primarily the use of the Malayalam language, particularly in dramas and songs. According to Table 1 there are 1636 members in the seven official Malayalee organizations, a number which would be roughly ten percent of the Singapore Malayalee population. Therefore there are a substantially larger number of Singapore Malayalees who are not involved with the 
organizations. 5 Yet Table 1 still indicates a larger portion of the Malayalee population than is actually involved with these associations. First, people may join multiple organizations and there tend to be a core group of people who are involved with several of the organizations. Secondly, membership in an organization takes a fee, but one does not necessarily have to participate. The majority of members just attend whatever events they like during the year. Also, having a large membership is not necessarily a goal of all the organizations, for example the SKKN only takes members who will be able to help with the various plays and singing contests.

Membership in these organizations implies that one has an active interest in the Malayalee community and the particular causes of that organization. It may also imply a certain amount of prestige, especially to those who are more active in the organizations, as being 'more real' or 'good' Malayalees, as compared to those who are considered (and consider themselves) as 'not very good' Malayalees, that is, those who do not know Malayalam or participate in any of the organizations (see Chapter Four).

The majority of those heavily involved in these organizations are those who are literate in Malayalam and

5 The organizations usually have different kinds of memberships, such as family, lifetime, yearly, or individual memberships. However, a family membership does not necessarily mean the participation or even interest of the entire family. 
feel a need to promote the use of the language. They are primarily first generation singapore Malayalees who have witnessed firsthand the changing (some would say decline) of Malayalee culture in singapore and want, at least, to do something to slow that change. For example, sarojini is a first generation Singapore Malayalee who came to Singapore in 1953 when she was around thirteen years old. She is now involved with several of the Malayalee organizations, especially as an actress with the SKKN and KNBL and the SKA, of which she is also the vice president. She feels it is important for Malayalees to learn Malayalam in order to communicate with elder Malayalees and those back in Kerala. It is only through the language that they will be able to keep the culture intact, as some things just do not come across the same in English.

The above example of Sarojini is typical of many who are heavily involved in the Malayalee organizations; however, there are exceptions. For example, Ara, the President of the SKA, is a second generation Singapore Malayalee. He speaks and understands Malayalam, but cannot read or write it. He feels that knowledge of one's language and its literature is imperative to learning and understanding one's culture. This is why, he says, it will be very important for his children to spend time in Kerala, at least enough time to learn the language better.

The audiences for the cultural shows range in size from 
around five hundred at the smaller shows to perhaps two thousand at the largest onam show in the Victoria Theatre near downtown Singapore. There were nearly one thousand, for instance, at the NBKL's onam show at the SLF Auditorium in August of 1992 and the show was sold out in advance. The majority of the audience, of course, at least understood Malayalam since most of the show was in Malayalam. However, there were exceptions. For example, I happened to meet one Catholic woman, Anne, who mentioned that she had grown up in Malaya and Singapore and understood no Malayalam. When I asked her why she came to the show, she said that she enjoyed the singing and dancing, and that it seemed to be a "very Malayalee thing to do."

Again, there are large numbers of Singapore Malayalees who do not attend, nor have any interest in these shows. For example, they are viewed by many Christians and Muslims as more 'Hindu' things to do, although I knew of several Christians and Muslims who attended the shows regularly. one Muslim informant cited the Hindu origin myth behind onam as enough reason not to attend an onam show, yet another pointed out that onam is also a harvest festival and a holiday that is celebrated by all Malayalees. Several of my informants also noted that attending these cultural shows was something that primarily the more 'typical' Malayalees did.

The people involved in the organizations and those who 
attend the various events that the organizations put on look at these events as chances to view and participate in their own culture and heritage. The use of the Malayalam language is promoted, and people are able to view and participate in something they feel should be much more in their lives, yet cannot be due to the circumstances of living in singapore.

In seeking an explanation for these patterns of behavior, once again the instrumentalist and primordialist modes of thought come into trouble. Either of these modes of thought would work well in a study of any one of the above mentioned Malayalee groups. Either could explain the significance of these groups in carrying on the Malayalee identity, but neither could deal with the question of why so many Singapore Malayalees have little or nothing to do with these organizations, nor do they have any interest in doing so. They do not group together to maximize their interests, nor do they all, or even most, come together based upon any kind of primordial feelings. Yet the Malayalee identity remains important to them. To understand this better it is necessary to look more closely at an important symbol of Malayalee ethnicity: the Malayalam language. 


\section{CHAPTER IV}

\section{MALAYALAM LANGUAGE IN SINGAPORE}

The Malayalam language is a very powerful symbol of Malayalee ethnicity in singapore. What is most interesting is the somewhat paradoxical nature of this symbol. On the one hand the majority of Malayalees in Singapore are not fluent in speaking the language, and certainly a large majority cannot read or write Malayalam. This is especially true among younger Malayalees born and raised in singapore. Those who were educated in Kerala before migration to Singapore are much more likely to read and write Malayalam. on the other hand, all of the Malayalees in Singapore think of Malayalam as being their language, their 'mothertongue', although they may not speak it at all. It is quite possible, again especially among the younger generation, that they were raised speaking English at home and educated primarily in English while learning Malay, Tamil, or even Mandarin as a second language.

This is what Eastman (1984:259) describes as an associated language:

A particular 'associated language' is a necessary component of ethnic identity but the language we associate ourselves with need not be one we use in our day-to-day lives... It need not even be one we know at all. 
Eastman sees language use as merely one aspect of ethnic identity. Therefore the language may change while the ethnic identity does not. This is indeed the case among the Singapore Malayalees, particularly, as will be shown, among those raised and educated in singapore. English is now the most widely used language among Singapore Malayalees. However, English is still not considered as 'their' language. That distinction still belongs to Malayalam. Perhaps the significance of Malayalam as a symbol of Malayalee ethnicity is best illustrated by the feeling of estrangement from their own culture expressed by many Malayalees who do not speak Malayalam well. For example, one evening at the neighborhood coffee shop I happened to meet a Malayalee friend, William, who did not speak or understand any Malayalam. I had forgotten this fact and as he got up to leave I said to him, in Malayalam, "pinne kaanam" (see you later). He looked at me and said "I'm lost, and I always will be."

Although this statement was made in a somewhat kidding manner, it is an excellent illustration of the feeling that many Malayalees expressed. They feel that they are Malayalees, however not necessarily good Malayalees because they do not speak Malayalam. Yet they also admit that they are not willing to do anything about it due to lack of time and/or lack of interest. The expression of this kind of sentiment was not at all uncommon; in fact I often heard 
statements such as: "It's a shame that we (or I) do not speak our (my) own language".

Malayalam is an important symbol of Malayalee ethnicity for three main reasons. First of all, it is the language of their ancestors and the Malayalee home state of Kerala, not to mention many elder Malayalees in Singapore, some of whom speak little or no English.

Secondly, Malayalam is a distinct language, separate from Tamil, another Dravidian language spoken by the majority of Indians (Tamils) in Singapore. Tamil had been, until just a few years before my fieldwork, the only Indian language that could be studied in school as an official singapore language, and was dubbed by the government as the 'mother tongue' of Singapore Indians. The majority of Malayalees, and other non-Tamil Indians for that matter, have never considered Tamil to be their 'mother tongue', and many have resented the fact that it has been so designated for them. In fact I have found the majority to choose Malay as their second language in school over Tamil (see Table 2). Malay is usually cited as easier to learn because the script is romanized; it is more widely used in the region; and Muslims cite it as the language of Islam in the region. As one Malayalee Catholic told me: "We are not Tamil, so why should my son learn Tamil?... Malay will be much more useful to him in this region."

Finally, language in singapore is often seen as the 
vehicle for culture. For example, it is often stressed in government campaigns that knowledge of one's "mother tongue" is essential to fully understand one's own history and culture, and therefore one's own place in singapore's multiracial, multicultural society (never mind the fact that only four of a possible multitude of languages are regularly taught in schools).

Over the years in Singapore it has been very difficult for most Malayalees to get any education at all in Malayalam, although there have been, at times, Malayalam classes held on the premises of the various organizations. This is because parents have felt that their children's success in the English-based school system would be much better facilitated by the use of English in the home. This, along with the lack of facilities in which to learn to read and write Malayalam, has led to the situation now among a large number of second generation Singapore Malayalees: they can understand spoken Malayalam but they cannot speak it much if at all, nor can they read or write it.

This generationally declining use of Malayalam is generally true among all of the Malayalee groups, although there are some specific differences. For example, Table 2 shows information on a sample of singapore Malayalees and their knowledge of Malayalam. What the table most clearly shows is a severe decline in the numbers of those able to read and write Malayalam from the first generation to the 
second. The number of those able to speak fluent Malayalam also decreases significantly, from all of those in the first generation to less than half of those in the second generation. This decrease seems to be most prominent among the Malayalee Catholics, which is part of the 'Westernized' perception of them discussed in Chapter Three. ${ }^{1}$ The ability to understand Malayalam seems to decrease much less than the other categories at this point, but I would expect it to decrease much further in the third generation.

Most of my informants agreed that the use of Malayalam was most widespread among the Malayalee Hindus. For example, several Malayalee Christians expressed what one woman told me in particular: that "in order to know the real Malayalee culture you need to talk to the Hindus." The Hindus are often regarded as being more true to 'real' Indian culture, that is they have remained with an Indian religion rather than switching to a Western one. Therefore theirs is seen as a more authentic version of Indian culture, no matter how long the other religion may have existed in India.

However, among the Malayalee Hindus, I found very much the same situation as among the rest of the Malayalee population: those of the generations born and raised in Singapore are much less likely to be fluent in the language,

$1 \mathrm{Lu}$ (1979) comes to similar conclusions in a comparison of Malayalee Catholics and syrian Christians. 


\section{Table 2}

Knowledge of Malayalam in Singapore by Generation and Religion. ${ }^{2}$

$\begin{array}{ccl}\underline{\mathrm{Y} / \mathrm{N}} & \underline{\text { Second Lanquage }} \\ \text { Speak Understand Read } & \text { Malay }\end{array}$

Hindus

ist gen.

$17 / 0$

$17 / 0$

2nd gen.

$17 / 5$

$22 / 0$

$17 / 0$

$5 / 17$

$\mathrm{n} / \mathrm{a}^{3}$

11

$\mathrm{n} / \mathrm{a}$

Catholics

ist gen.

2nd gen.

$13 / 0$

$2 / 14$

$13 / 0$

$10 / 6$

$11 / 2$

$0 / 16$

$\mathrm{n} / \mathrm{a}$

13

$\mathrm{n} / \mathrm{a}$

0

Syrian Christians

\begin{tabular}{llllll} 
1st gen. & $6 / 0$ & $6 / 0$ & $6 / 0$ & $\mathrm{n} / \mathrm{a}$ & $\mathrm{n} / \mathrm{a}$ \\
2nd gen. & $2 / 4$ & $6 / 0$ & $1 / 5$ & 6 & 0 \\
Muslims & & & & & \\
1st gen. & $4 / 0$ & $4 / 0$ & $4 / 0$ & $\mathrm{n} / \mathrm{a}$ & $\mathrm{n} / \mathrm{a}$ \\
2nd gen. & $1 / 2$ & $2 / 1$ & $0 / 3$ & 3 & 0 \\
\hline
\end{tabular}

2. I assembled this table by compiling a list of all those on whom I had this information. I then took only one example from each generation in each family. I feel this method gives a better idea of actual situations of Malayalam knowledge in Singapore. Whereas if I had just used the numbers of people on whom I had this information, the table would have reflected numerical dominance of a few large families. I found that members of the same family and generation, especially siblings raised in singapore, tended to have similar knowledge of Malayalam. I came across only one exception to this during my fieldwork. It involved two brothers raised in singapore. One brother returned to Kerala to marry a Kerala Malayalee woman. While there for the wedding the father became ill and suddenly passed away. Due to this tragedy the younger brother wants absolutely nothing more to do with Kerala nor does he have any interest in Malayalam. The older brother, however, has become very fluent in Malayalam and uses it as the primary language in the home. In an exception such as this, both were listed in the table.

In this table I take first generation to mean those who migrated to Singapore (or Malaya) and had at least a 
substantial portion of their education in India. By second generation I mean those who were raised and educated in Singapore (or Malaya). I did not include a third generation in this table because I did not have enough examples. Where I did have a prominent third generation, such as among one family that had been in singapore since the 1920's, I included both the parental and younger generation under the second generation category.

It is important to note that although many people represented in this table claimed to be fluent and even literate in Malayalam, English remains their primary language, at least outside of the home. This is especially true among those of the second generation. For example, one day I happened to meet two men in their late teens studying for an exam. Both claimed fluency in Malayalam due to use in the home and both had learned to read and write it some years earlier through the Guru Kulam. It was interesting, however, that they communicated each other in English. I also found the same to be true among sibling groups who spoke Malayalam. In fact, I was told by one informant that he used Malayalam with his brothers only for "security purposes", that is, only when they did not want others to understand what they were saying to each other. As would be expected, the use of Malayalam as the primary language was much more common among the first generation. I did not, however, meet any Singapore Malayalees, with the exception of some Malayalee Muslims (see note 4, this chapter) who were not fluent in English and seemed to know it just as well, if not better, than Malayalam.

3. This distinction does not generally apply to the first generation of Singapore Malayalees because they were educated in Kerala, so their choices were different from those educated in Singapore who must choose between Malay and Tamil as a second language. However, many of the first generation have picked up Malay for use in the markets, etc., and many also speak Tamil and/or Hindi. 
much less read and write it. For example, Raman is twentyeight years old, working for a Singapore based European electronics company. Having graduated from a university in the United States and being trained in Europe by the company, he speaks three or four languages, but Malayalam is not among them. This is despite the fact that both of his parents are literate in Malayalam and his mother is active in Malayalee organizations. This situation is by no means isolated; it is common among many Malayalee Hindu families.

Among the Malayalee Christians, the Catholics are usually recognized, by themselves and by others, as being the most 'westernized' and the least likely to use Malayalam (see Chapter Three; Lu 1979). For example, all of the Malayalee Catholics I met who were fluent in Malayalam were of the older generation and had been educated in Kerala, with the exception of one twenty-one year-old woman who happened to have lived with relatives in Kerala for five years.

But among the Syrian Christians the Malayalam situation is not much different, although they are seen by other Malayalees, especially the Catholic Malayalees, as being more 'traditional'. The biggest difference is that in both of the syrian churches, services are conducted in Malayalam bi-weekly, alternating with English services. Formerly the services were all in Malayalam, but they decided to switch to the current format to keep the interest of younger 
members who may not be able to understand the Malayalam.

I know the least about the Malayalam situation among the Malayalee Muslims. However, I think it would not be out of place for us to assume that the situation is pretty much the same for them as it is for the others. For example, in the one Travancore Muslim family that I was able to meet, all those of the first generation (i.e. the father and his parents-in-law) were fully literate in Malayalam. However, those of the second and third generations (the wife and children) could only understand and speak Malayalam. The children only used Malayalam with the grandparents, who did not speak English. With the parents they were used to communicating in English and felt somewhat shy to use Malayalam. The same situation existed for the Malabar Muslims I met: their children tended to be much more proficient in English and Malay and knew little or no Malayalam.4

In spite of the fact of generationally declining knowledge of Malayalam among singapore Malayalees, and in

4 I did not meet as many Malabar Muslims as I would have liked, in part due to the fact that I had just started learning Malayalam. I went to the Malabar Mosque on several occasions to attempt to meet Malabar Muslims, but I often found only those who spoke no English, only Malay, Malayalam, or Tamil. With my very limited Malayalam I was able to find out that some of these people were visiting from Malaysia or Kerala, or were migrants from Kerala who had never learned English. From the interviews I did with those who did speak English, I got the impression that the majority were in a similar situation to other Malayalees: the children were not learning Malayalam but had a good knowledge of Malay and English. 
fact because of it, there are those in singapore who are promoting the learning and use of Malayalam. Since Malayalam is one thing all of the Malayalees have in common, whether they speak it or not, and because language is seen as a vehicle for culture in singapore, it is seen as the biggest factor in uniting the Malayalee community.

Since the regular schools do not offer Malayalam, the options for people to learn the language are limited to a few situations. First of all there is the possibility of formal Malayalam classes which students could take rather than Malay or Tamil. In recent years the government has changed its stance which recognized Tamil as the 'mothertongue' of all singapore Indians and has allowed Indian minorities to set up their own classes, although not yet in the regular schools. For example Punjabi and Gujerati children are able to learn their respective languages at their local associations.

The Malayalees have also been trying to set up an official language learning program and have created an "Umbrella organization" including the seven official Malayalee organizations (although the Narayana Mission has backed off from this somewhat as it is problematic for them to be officially recognized as a "Malayalee" organization) to oversee the organization of a Malayalam teaching program for school children and other Malayalee youth. During the time of my fieldwork, however, this plan had been stalled 
due to disagreement among the various organizations as to how to go about hiring qualified teachers for the program. If the program is set up and there is enough interest, which they believe there is, then there would be Malayalam classes held at the premises of some of the various organizations (i.e. SKA, SKKN, MMJ, NBKL).

secondly, there are more informal classes periodically offered by some of the organizations on the weekends. The SKA in particular has often offered classes in the past. They were not offering classes during the time of my fieldwork, but they did have a teacher and they were waiting for enough students to express interest in taking the classes. ${ }^{5}$ The Guru Kulam also has offered Malayalam classes in the past and started with classes again in July 1992 (as mentioned above in Chapter Three). In these classes the students generally learn to read and write the language as they usually have at least some proficiency in speaking the language at home, or at least the ability to understand it.

The problem with this type of language learning is that the students only have class for one and a half hours each

5 Both the SKA and the Guru Kulam have offered Malayalam classes in the past, but I was not able to get specific dates. At least two of my informants listed in Table 2, the two men in their late-teens (note 2, this chapter), had learned to read and write Malayalam at the Guru Kulam four to five years before. The Malayalam teacher for the SKA has also taught a course at least once within the previous two years. 
week on Sunday and with everything else they have to do, the Malayalam classes cannot really become a priority. For example, working adults have a forty-four hour six-day work week and students already have two languages to study in school (English and usually either Malay or Tamil) along with their other courses. This is also the main reason many people gave me that most Malayalees have not learned much Malayalam: there is already too much to do.

Finally, the form of Malayalam learning most vigorously promoted in Singapore, especially by several individuals involved with the Malayalee organizations, is the sole use of Malayalam in the home. This is in contrast to the large number of Malayalee families that switched to speaking English in the home to make it easier for their children in the English-based school system. This switch is the main reason why many Malayalees today may understand some Malayalam, but may speak little or no Malayalam.

The sole use of Malayalam in the home is often a topic at one of the cultural shows described above. It is seen as the best way for children to become familiar with their language and culture. This method is promoted as being possibly the only way to keep the Malayalam language in use in singapore, since it is not possible to use it in most public situations and it cannot be learned in school. As an anthropologist studying Malayalam in Singapore, I also found myself being used as a symbol for the use of 
Malayalam. For example, the mother of a Hindu Malayalee in the neighborhood where I was staying told her son: "This American comes all the way to Singapore to learn Malayalam and you can't bother to learn any." I was also asked to speak a few Iines in Malayalam at the Kerala Naval Base Library's onam show in order to show that I could learn it, therefore it would not be that difficult for Malayalees to learn it.

This example of Malayalam use and its symbolic importance in singapore is very enlightening in regards to ethnicity theory. First, as primordialist theory would dictate, language, along with place of origin play an important role in Malayalee ethnicity. But how are we to deal with the fact that the majority of Malayalees in Singapore are not bothering to learn the language which they consider to be the base of their culture? And contra instrumentalist tenets, Malayalee ethnicity in singapore has not formed to protect any common economic or political interests. In fact, as mentioned in Chapter Two, the Singapore Malayalee community has become more fragmented since the withdrawal of the British in the early 1970's, and the use of Malayalam, the most important symbol of Malayalee ethnicity, has decreased significantly over the years.

with the practice theory of ethnicity, as laid out by Bentley (1987), we are much better able to take all of these themes into account. As Malayalees have grown up within the 
modern nation-state of Singapore, they have had to deal with entirely new structures, those which the first generation of Singapore Malayalees would not have had to deal with when growing up. Most significant is the contradiction they have had to work through. On the one hand, as a small minority in a country where English is the most important language of business, trade, and education, they have found the use of the Malayalam language to be impractical and unimportant most of the time outside of the home. As one informant told me: "Speaking Malayalam won't get me a good engineering job." on the other hand, in singapore, language is seen as the most important vehicle for culture, a fact that was stressed by many of my informants and that is stressed by the government itself. This is seen as the basis of singapore's multiculturalism, which is also the base of Singaporean culture (Benjamin 1976).

This contradiction has led to a feeling of alienation from their own culture for many Malayalees. They do not feel alienated from Singaporean culture, or Indian culture, both of which can be seen as being made up of multilingual and multicultural groups. The alienation is felt from Malayalee culture (whatever that may be, considering the diversity of that category itself) because of the loss of the language.

on the one hand, the use of the Malayalam language has severely decreased due to government policies in education, 
a lack of time (and interest) to learn it through alternative education, and, most importantly, sheer impracticality. On the other hand, the singaporean idea of multiculturalism and the significance of language as a means to cultural knowledge has increased the importance of the Malayalee identity and the significance of Malayalam as a symbol of Malayaleeness.

Therefore many Malayalees feel alienated from what they consider to be their own culture. As William, mentioned above, and several others told me on separate occasions: "I know nothing about my own culture." Culture itself has come to be considered not as the everyday happenings of life, but as the parts of everyday life that are somehow missing from the everyday lives of most Singapore Malayalees. 
CHAPTER V

\section{CONCLUSIONS}

It was mentioned in Chapter Three that the majority of those heavily involved with Malayalee organizations were first generation Singapore Malayalees who were fluent and literate in Malayalam and had seen the decline of the use of their language in singapore first hand. Following the discussion in Chapter Four we would expect any younger, upand-coming leaders of the Malayalee associations to have overcome feelings of alienation by having learned to at least communicate fluently in Malayalam, if not becoming fully literate in it.

Such is the case among those few younger leaders of the Malayalee associations I was able to meet. The case of Keshavan is an excellent example. He was raised in Singapore and taught Malayalam by his parents. He also studied on his own and became fully literate in the language as a teenager. At the same time he studied Tamil in school rather than Malay. Unlike many other Singapore Malayalees his age, Keshavan never expressed a feeling of alienation from his own culture. He did, however, express a feeling of frustration over the fact that so many others did not know Malayalam. He feels that at least Malayalam should be used 
in the home and that it is better for Malayalees to learn Tamil in school rather than Malay as it is at least an Indian language which is related to Malayalam.

Keshavan's knowledge of Malayalam, the core symbol of Malayalee ethnicity in singapore, has allowed him to view and experience Malayalee ethnicity a bit differently from most others of his generation. Since he learned and used Malayalam in the home rather than English and because he is both fluent and literate in Malayalam now, he has that link which is perceived as being vital to one's culture in Singapore. He can view himself, and be viewed by others, as more of a "good" Malayalee, as opposed to those who view themselves as not very good Malayalees because they do not know Malayalam. that:

Bentley's discussion again helps us here when he notes

As individuals develop new ways of dealing with a changing world, old truths erode; as what was formerly inconceivable becomes commonplace, degrees of sharing and affinity, hence ethnic identities, become problematic....under these conditions ethnic symbolism is likely to take on different meanings for differentially adapted segments of a population (1987:43).

We can see two aspects of history coming together to form the particular structure of Malayalee ethnicity in singapore today. On the one hand, Malayalees were able to use Malayalam outside of the home less and less often, especially after the breakup of the Malayalee areas such as 
the Naval Base, while the use of English became increasingly more important, especially in education and the job market. on the other hand, the knowledge of one's "mother tongue" as a means of knowing one's culture and heritage became emphasized at many levels of Singapore society, especially in education. This situation has led to the feelings of alienation many Malayalees have from their own culture in Singapore:

The unprecedented possibilities created by rapid political and economic change may be experienced positively as opportunities for innovation and interest advancement, but they are likely also to be experienced negatively as disorienting and alienating (Bentley 1987:44).

When the Malayalees were merely sojourners in Singapore, their identity as Malayalee was never problematic, although it was highlighted with more intensive contact with Tamils and other Indian groups. But this changed as Singapore became a sovereign nation-state and Malayalees began to turn their attention from the home state of Kerala to the new home of Singapore. The same process has taken place among the singapore chinese in their interests turning from mainland china to singapore. For example, Carstens (1975) has shown how Chinese associations have been adapted to fit the needs of the singapore situation, and (1988) how Chinese publications in singapore and Malaysia have changed through the years reflecting the concerns of Southeast Asian Chinese. 
The Malayalees' knowledge of English and willingness to speak English in the home gave them an advantage, a head start, in education and employment especially after 1965 when Singapore became independent from Malaysia and English took over in popularity (Li 1989:118). This can most clearly be seen in comparison to the case of the Malays, most of whom had been educated in Malay, not English, and were therefore caught unprepared for the significance English took on in higher education and the job market in Singapore (English is now mandatory for all students; Li 1989: 115-119) .

In order to understand fully the phenomenon of ethnicity it is imperative that it be studied at national and regional levels and within historical and national contexts. The formation of ethnic groups, categories, and identities is a historical process which involves people in situations of change, such as migration, and more intensive contact with other peoples (Sarna 1978; Yancey et.al. 1976). The majority of Malayalees did not go to singapore expecting to stay on, raise their families there, and eventually become citizens of a newly formed nation-state. But that is exactly what happened, and as this process has taken place the form and significance of Malayalee ethnicity in Singapore has changed.

The first generation came to singapore as immigrants or sojourners and ended up becoming citizens or permanent 
residents. As the use of Malayalam became more impractical in the public sphere, fewer Malayalees learned it, and many parents switched to speaking English in the home to give their children an advantage in the English-based school system. This has led to many of the first generation Singapore Malayalees feeling an overall fading of Malayalee culture in singapore since the breakup of the Malayalee communities in the early $1970^{\prime}$ s and with the decline in the Malayalam language.

This point was best expressed to me by Mr. Jacob, a seventy year-old syrian christian, when he told me a story of how he and a friend had been standing outside a shop in Singapore in the early $1950^{\prime} \mathrm{s}$. As they watched an Indian boy and a Chinese girl pass by arm in arm, Mr. Jacob said to his friend: "this is going to happen to our children." He then told me that it has happened to his and others children and it will continue to. This is one of the reasons he feels that the Malayalee culture is slowly being assimilated into the more dominant cultures of singapore and the Malayalam language is slowly but surely disappearing. On the other hand, the second generation of singapore Malayalees acknowledges the loss of Malayalee culture through a feeling of alienation, of not knowing about one's own culture. The particular form of Malayalee ethnicity that exists in singapore today is best understood in these terms. It has come about through historical processes: 
migration to a new land, the converging of many different peoples in a new political and economic system, and the building of the nation-state of singapore.

The Malayalees have maintained ethnic boundaries with the idea that they have a different 'mother tongue' than the majority of Singapore Indians. The Singapore Malayalees are conscious of their ethnic identity, yet to the vast majority that consciousness is enough; it is not necessarily something to be acted upon.

As the structures of life have changed in singapore over the years, habitus, the underlying strategies people use to deal with the world, has changed, most markedly among the different generations. With the theory of practice and the concept of habitus we get a much clearer picture of Malayalee ethnicity in Singapore today. 'Malayalee' has remained a significant identity in spite of the availability of other choices and the lack of knowledge of its core symbol, the Malayalam language, by a large number of singapore Malayalees. Much of this can be explained as due to the focus in singapore on the importance of knowing one's 'mother tongue' as the means to knowing one's culture and heritage on the one hand, while on the other hand gaining a knowledge of Malayalam has been both difficult and impractical for most Singapore Malayalees, especially among the second generation.

The Singapore Malayalees have become part of an overall 
Singaporean culture, which is based on the idea of multiculturalism (or multiracialism; c.f. Benjamin 1976). There is a consciousness of this singaporean culture; however, it is rarely spoken of as such. Rather it is expressed as being part of a multicultural, multilingual society-- Chinese, Malay, and Indian. The focus on multiculturalism has come about due in part to singapore's colonial past as a convenient organizing principle, and it has remained as an important organizing principle in the building of the nation-state of singapore. With this emphasis on multiculturalism the sense of a distinctive Malayalee culture will remain in singapore, as will the sense of alienation from it felt by many Malayalees.

It is perhaps most interesting that there has not been a wider revival of interest in Malayalam language learning. It is regarded as something which is important and necessary for the understanding of Malayalee culture, yet it is also seen as impractical and unnecessary in today's singapore.

A much wider interest in learning Malayalam could come about, however, if Malayalam becomes available for students to learn as their second language in school. As mentioned above in Chapter Four, there has been a movement to do just this and an 'umbrella organization' encompassing the existing Malayalee organizations has been formed. But the Malayalam program had not yet gotten off the ground as of the end of my fieldwork in 1992. 
The popularity of this program, when it gets started, will depend very much upon its convenience to singapore Malayalees. With such a small portion of singapore's population it will not be taught at schools but at Malayalee organizations, so the number of classes and their locations will be important. For example, of the four Malayalee organizations with space to hold classes, three are located in or near the Little India area of Singapore and would seem to be somewhat out of the way for most students.

There are problems to be overcome, but the structures for a wider scale revival of interest in Malayalam are in place. However, it seems unlikely that this will come about in the near future without a more practical need for the use of Malayalam. 
APPENDIX

INTERVIEW QUESTIONS

\section{Organizations}

1) How many members belong to the organization? How many people does it serve?

2) Who makes up this membership-- what specific communities does the organization serve? (e.g. Hindus? of particular caste backgrounds?) Is there a difference between those whom the organization was meant to serve (e.g. the whole Malayalee community) and those who actually use it the most (e.g. Hindus)?

3) What are the major goals of the organization?

4) What events are sponsored by the organization?

5) How frequently do members (or others) tend to use the organization or attend its events?

6) Do most members live within a specific area or do they come from different places in singapore?

7) What is the relationship of this organization to other Malayalee organizations and other Indian organizations?

8) Are there specific reasons why people will join the organization or take part in its activities?

\section{other People}

1) What organizations do you belong to (Malayalee and other, e.g. religious)? What activities of these and others do you usually take part in?

2) How often do you use or attend the organization(s)?

3) What do you perceive as the major goals of the organization(s)? 
4) How often do you and your family or friends speak Malayalam?

5) Can you read and write Malayalam? can many of your family and friends? What other languages do you speak, understand, read and write? How often do you use them?

6) (How) do you feel that Malayalam is important for Malayalees? Why? Is its use increasing or decreasing in singapore? Will it survive here?

7) Do you have many relatives in singapore? (If possible, list them.)

8) Do you keep a close relationship with relatives (or others) in India? What is your relationship with them? How often are you in contact?

9) Have you been to Kerala? How does it compare to Singapore? (Relations between Malayalee groups?)

10) Do all your relatives belong to the same religious group? (inter-religious marriages?)

11) Do you have Malayalee friends outside of your religious group?

12) How often do you associate with Malayalees from outside your religious group?

13) What attitudes do Malayalees have towards other religious groups (or others within the same religion)? What attitudes do other religious groups (or others within the same religion) have towards Malayalees?

14) What is your occupation? Is this a common occupation among Malayalees? Do different groups of Malayalees tend to have common occupations?

15) Do Malayalee occupations tend to differ from others? How? Do Malayalees tend to think about their occupations differently?

16) When did you (or your ancestors) come from India? What part of Kerala did you (or they) come from? Do you know of many others here from that area? How have things changed for Malayalees in singapore since then (the whole situation, relations with other Malayalees, with other Indians, and others)? 
17) How do you, and/or others, show to other people that you are Malayalee? How do you differentiate between other Malayalees, and other Indians-- what are the important factors?

18) What do you consider to be traditional Malayalee dress? How often do you and/or your family members use it? What does wearing it mean to you? How is it different from others?

19) Are Malayalees different from others in the use of etiquette or the food they eat? How? (Differences between Malayalee groups?)

20) What attitudes do Malayalees have towards others? (e.g. Chinese, other Indians). What attitudes do they have towards Malayalees?

21) What attitudes do Malayalees have toward life in general? How does this differ from other Indians? Other Singaporeans?

22) Are their certain core traits that Malayalees have in common? How do the different religious groups of Malayalees differ in these traits? Are there other major differences?

23) Are their certain core traits common to Indians in singapore? How do singaporeans from other ethnic groups view Malayalees as Indians? 
REFERENCES

Anderson, Benedict

1983 Imagined Communities: Reflections on the Origins and Spread of Nationalism. London: Verso.

Arasaratnam, Sinnappah

1970 Indians in Malaysia and Singapore. Kuala Lumpur: oxford University Press.

Barth, Frederick

1969 Ethnic Groups and Boundaries. Boston: Little, Brown.

Bassett, D.K.

1964 The Historical Background, 1500-1815. In: G.W. Wang, ed. Malaysia: A Survey. New York: Praeger.

Benjamin, Geoffrey

1976 The Cultural Logic of Singapore's 'Multiracialism'. In: Riaz Hassan, ed. Singapore: Society in

Transition. Kuala Lumpur: Oxford University Press.

Bentley, G. Carter

1987 Ethnicity and Practice. Comparative studies in Society and History 29:24-55.

Bourdieu, Pierre

1977 outline of a Theory of Practice. Cambridge: Cambridge University Press.

Carstens, Sharon A.

1975 Chinese Associations in Singapore Society. occasional Paper No. 37, Institute of Southeast Asian Studies.

1988 Chinese Publications and the Transformation of Chinese Culture in Singapore and Malaysia. In: J. Clushman and Wang Gungwu, eds., Changing Identities of the southeast Asian chinese since World War II. Hong Kong: Hong Kong University Press.

Eriksen, Thomas Hylland

1993 Ethnicity and Nationalism: Anthropological Perspectives. London: Pluto Press. 
Eastman, Carol

1984 Language, Ethnic Identity, and Change. In: J. Edwards, ed., Linguistic Minorities, Policies and Pluralism. London: Academic Press.

Geertz, clifford

1973 The Integrative Revolution: Primordial Politics and Civil Politics in the New states. In: The Interpretation of Cultures, C. Geertz. New York: Basic.

Handelman, Don

1977 The Organization of Ethnicity. Ethnic Groups $1: 187-200$.

Jain, Ravindra $\mathrm{K}$.

1970 South Indians on the Plantation Frontier in Malaya. New Haven: Yale University Press.

Jeffrey, Robin

1987 Governments and Culture: How Women Made Kerala Literate. Pacific Affairs 60:447-472.

Keesing, Roger M.

1975 Kin Groups and Social structure. New York: Holt, Rinehart, and winston.

Keyes, C.F.

1976 Towards a New Formulation of the concept of Ethnic Group. Ethnicity 3:202-213.

Li, Tania

1989 Malays in Singapore: Culture, Economy, and Ideology. Singapore: Oxford University Press.

Lu, Lily Lih-Ping

1979 The Indian Christians: Hierarchy in an Egalitarian Religious Community. Academic Exercise, Department of Sociology, University of Singapore.

Mani, A.

1977 The Changing Caste-structure Amongst the Singapore Indians. Master's Thesis, Department of Sociology, University of Singapore.

Mathew, Mary Eapen K.

1974 Marriage Patterns and Community Identity Among the Syrian Christians in Singapore. Academic Exercise, Department of Sociology, University of Singapore. 
Menon, Suresh

1976 Role of Religious Institutions and Associations in a Malayalee "Neighborhood". Academic Exercise, Department of Sociology, University of Singapore.

Nagata, Judith A.

1974 What is a Malay? American Ethnologist 1:331-350.

Netto, George

1961 Indians in Malaya: Historical Facts and Figures. Singapore: The Author.

Rajakrishnan Ramasamy

1988 Sojourners to Citizens: Sri Lankan Tamils in Malaysia 1885-1965. Kuala Lumpur: University of Malaya.

Sandhu, K.S.

1969 Indians in Malaya: Immigration and settlement 1786-1957. Cambridge: Cambridge University Press.

Sarna, Jonathan D.

1978 From Immigrants to Ethnics: Toward a New Theory of "Ethnicization". Ethnicity 5:370-378.

Sinha, Vineeta

1987 Hinduism in Singapore: A Sociological and Ethnographic Perspective. Master's Thesis, Department of Sociology, National University of Singapore.

Thomas, Sara

1956 The Malayalees of Singapore: A Study into Their Customs, Manners and Mores which Keep Them a Separate Community. Academic Exercise, University of Malaya, singapore.

Thomas, Suja susan

1991 "Syrian Christians" in Singapore: Ethnicity in Process. Academic Exercise, Department of Sociology, National University of Singapore.

Turnbull, C.M.

1972 The Straights settlements 1826-67: Indian Presidency to crown Colony. Singapore: University of oxford Press.

1989 A History of Singapore 1819-1988. Singapore: University of Oxford Press. 
Yancey, William L.: E.P. Ericksen; and R.N. Juliani

1976 Emergent Ethnicity: A Review and Reformulation. American Sociological Review 41:391-403. 